\title{
Yaşlı kalça kırığı cerrahisi sonrasında ağrılı kalçaya yaklaşım
}

\author{
Management of painful hip after elderly hip fracture surgery
}

\author{
Bülent Karslığlu, Tahsin Olgun Bayraktar, Yunus İmren
}

SBÜ Prof. Dr. Cemil Taşçıŏlu Şehir Hastanesi, Ortopedi ve Travmatoloji Kliniği, İstanbul

\begin{abstract}
Yaşlı nüfusunun artmasına bağlı olarak kalça kırıklarının insidansının artması kalça cerrahileriyle ilgili görülen komplikasyonların sayısının artmasına yol açmaktadır. Kalça kırığı cerrahisinde amaç ağrının giderilmesi, hastanın hızlı rehabilitasyonla hareketine kavuşturulması ve yaşamını bağımsız olarak sürdürmesi olmalıdır. Kalça kırığı sonrası osteosentez veya artroplasti yapılan hastalarda kronik ağrı görülebilir. Cerrahi sonrası ağrı hastaların sosyal yaşamlarını ileri derecede etkileyen, rehabilitasyona uyumu ve rehabilitasyon sürelerini azaltan hatta revizyon cerrahileri gerektirebilen bir durumdur. Bu makaledeki amacımız yaşıı kalça kırı̆̆ı cerrahileri sonrası ağrı sebepleri ve tedavilerini değerlendirmektir.
\end{abstract}

Anahtar sözcükler: kalça kırı̆̆ı; ağrı; rehabilitasyon
The increase in the incidence of hip fractures due to the increase in the elderly population leads to an increase in the number of complications associated with hip surgeries. The aim of hip fracture surgery should be relief of pain, rapid mobilization with accelerated rehabilitation, and survival of the patient without any assistance. Chronic ongoing pain may occur in patients who undergo osteosynthesis or arthroplasty after hip fracture Post-surgical pain is a condition that affects patients' social lives, decreases their adaptation to rehabilitation and may even require revision surgeries. In our article, we tried to reveal the causes of pain after hip fracture surgery in the elderly.

Key words: hip fracture; pain; rehabilitation
Y aşlanan nüfusun artması ile beraber, kalça kırığı sıklığının da 2030 yılında yaklaşık \%15 oranında artması beklenmektedir. ${ }^{[1]}$ Kalça kırığı sonrası cerrahide amaç ağrının giderilmesi, hastanın hızlı rehabilitasyonla hareketine kavuşturulması ve geri kalan yaşamını bağımsız olarak sürdürmesi olmalıdır. Kalça kırı̆̆ı, beklenen yaşam süresinde $\% 20$ azalma yaratırken bu hastaların \%20-50'si hayatlarının geri kalan kısmında bir yardımcıya ihtiyaç duyar. ${ }^{[2]}$

Ameliyat sonrası geçmeyen ve en az 3 ay süreyle devam eden ağrı, kronik devam eden ağrı şeklinde tanımlanmıştır. ${ }^{[3]}$ Cerrahi sonrası ağrı, hastaların sosyal yaşamlarını ileri derecede etkileyen hatta revizyon cerrahileri gerektirebilen bir durumdur. Hastalar sistemik olarak değerlendirilmeli ve ağrı sebepleri sistematik olarak irdelenmelidir. Ağrının hareketle artması ve dinlenmekle azalması tanıyı mekanik ağrı sebeplerine yönlendirirken, hareketle ilişkisiz ve sabah tutukluğunun eşlik ettiği ağrılar yangısal (enflamatuvar) ağrı sebeplerini akla getirir. Diğer sebeplerin dışlandığı yanıcı batıcı tarzda, iyi tanımlanamayan ağrılar nöropatik ağrı sebeplerini düşündürürken, beraberinde kilo kaybı, ateş, gece terlemesi gibi alarm bulguların varlığı habis patolojileri akla getirmelidir. ${ }^{[4]}$

Ağrının yeri tanıyı koymada oldukça yararlıdır. Radiküler ağrı gibi eklem dışı alandan kaynaklanan ağrılarda kalça muayenesi ile birlikte rutinde yapılan lomber muayene ile olası patolojiler ortaya konabilir. Nöropatik ağrı paternleri de radiküler ağrılara eşlik edebilir. Ağrı damarsal problemlerle birliktelik gösterebilir ve vasküler kladikasyo görülebilir. İnguinal bölgedeki ağrılarda inguinal herniler de göz önünde bulundurulmalı ve yaşlı popülasyonda sık görülen patolojiler olduğu akılda tutulmalıdır. ${ }^{[5]}$

- Uzm. Dr. Bülent Karslığlu, SBÜ Prof. Dr. Cemil Taşçıoğlu Şehir Hastanesi, Ortopedi ve Travmatoloji Kliniği, Darülaceze Caddesi No: 27,

Okmeydanı, Şişli, İstanbul Tel: 0505 - 8106373 e-posta: bukars@gmail.com

- Geliş tarihi: 21 Ocak $2021 \quad$ Kabul tarihi: 1 Șubat 2021

ORCID iD: Bülent Karslığlu, 0000-0001-6127-9672 • Tahsin Olgun Bayraktar, 0000-0001-6544-1710 • Yunus İmren, 0000-0002-8056-6156 
Eklem çevresi bölgede ağrı ise genellikle kalça eklemi tendon patolojilerinde de izlenmektedir. Iliopsoas tendiniti, iliotibial bant sendromu ve osteitis pubis cerrahi geçirmiş hastalar için de muayene sırasında akılda tutulmalıdır. Trokanterik bursit de kalça cerrahisi sonrası izlenebilen ağrı sebeplerindendir. ${ }^{[5]}$

Kalça kırı̆̆ı cerrahisinde en uygun cerrahi yaklaşım halen tartışmalıdır. Kemik kalitesine, kırık tipine, hasta yaşına ve beklentilerine göre osteosentez veya protez cerrahileri uygulanabilmektedir. Bu makalede amacımız, her iki cerrahi grupta da ameliyat sonrası ağrı sebepleri ve tedavilerini değerlendirmektir.

\section{OSTEOSENTEZ SONRASI AĞRILI KALÇA SEBEPLERI}

Yaşlı kalça kırıkları içinde en sık intertrokanterik tip kırıklar görülmektedir. ${ }^{[6]}$ Bu kırıklar genellikle internal tespit cihazlarıyla osteosentez amaçlanarak tedavi edilir. Ameliyat sonrası ağrılı kalçada ilk 3 haftada (erken dönemde) öncelikle akla gelmesi gereken klinik durum cerrahi saha enfeksiyonlarıdır. ${ }^{[7]}$ Cerrahi sahada akıntı, hiperemi, sıcaklık artışı ve şişlik uyarıcı bulgular olmalıdır. Hasta sistematik olarak muayene edilmeli, beyaz küre sayımı, C reaktif protein (CRP), eritrosit sedimentasyon oranı (ESR) gibi enfeksiyon parametreleri değerlendirilmelidir. Palpasyonda dalgalanma hissi (fluktuasyon) veren alan direkt grafi, ultrasonografi ve bilgisayarlı tomografi gibi çeşitli görüntüleme yöntemleriyle incelenmeli, enfeksiyonun derinliği ve apse oluşumu açısından araştırılmalıdır. ${ }^{[8]}$

Erken dönem osteosentez sonrası yüzeyel yara yeri enfeksiyonları için oral ya da intravenöz (i.v.) antibiyoterapiler ön planda iken, derin dokuyu etkileyen enfeksiyonlarda ve apse oluşumunda tedavi cerrahi drenaj ve i.v. antibiyoterapi olarak planlanmalıdır. ${ }^{[8]}$ Erken dönemde ve klinik olarak düşük dereceli bir enfeksiyon varlığında implant korunarak ve uygun antibiyoterapi eşliğinde sağaltım yapılabilir. ${ }^{[9]}$ Fistül, apse oluşumu ve osteomiyelitle de seyredebilen geç dönem enfeksiyonlarda ise tedavi cerrahi debridman ve implant çıkarımı olarak planlanmalı, kaynama sağlanmış olgularda i.v. antibiyoterapi ile devam edilmelidir. ${ }^{[9]}$ Kaynama sağlanamamış ise, genellikle iki aşamalı cerrahi tedaviler önerilmektedir. ${ }^{[9]}$ Birinci aşamada enfeksiyonun eradikasyonu, ikinci aşamada internal tespit veya protez cerrahileri ile rekonstrüksiyon sağlanabilir. ${ }^{[10]}$

Uygulanan tespit yöntemine güvenerek erken harekete kavuşturmak hastanın yatağa bağımlılığını ve buna bağlı gelişebilecek komplikasyonları önler. ${ }^{[11]}$ Özellikle stabil olmayan intertorakanterik kırıklar sonrası katı tespit yapılamaması ağrıyı artıran ve hareketliliği azaltan bir faktör olarak izlenir. ${ }^{[12]}$ Stabil olmayan bir kırık tipi implant yetmezliği ve kaynamama gibi komplikasyonlara daha açıtıtır.[13] Psödoartroz varlığında laboratuvar tetkikleriyle, ameliyat içi biyopsi ve kültürle psödoartrozun enfekte olup olmadığı değerlendirilmeli ve tedavi ona göre planlanmalıdır. ${ }^{[9]}$

Proksimal femoral çivi uygulanmış, ancak anatomik redüksiyon ve kararlı tespitin elde edilemediği intertrokanterik kırıklarda implantın femur başından dışa çıkması ve asetabulum kıkırdağına saplanma (cut-out) gözlenebilir. Cut-out komplikasyonu hem erken hem geç dönemde ağrı sebeplerinden biri olup revizyon gerektirmektedir. Caruso ve ark., kadın cinsiyet, Cleveland periferik zonlarından posterosuperior lag vidası yerleşimi ve tip - apeks mesafesinin 30,7 mm'den fazla olmasının risk faktörü olduğunu belirtmişlerdir. ${ }^{[14]}$ Enfeksiyon olup olmaması, proksimal femurdaki kemik stoğu, hastanın fonksiyonel durumu ve yaşam beklentisi, femur başı ve asetabulum kıkırdağının etkilenme derecesi ve osteoartrit varlığına göre revizyon cerrahilerinde osteosentez veya artroplasti seçilebilir. ${ }^{[15]}$ Özellikle instabil pertrokanterik kırıklarda medial kalkar desteğinin olmaması ve kayıcı kalça çivisi implantının çalışma prensipleri dolayısıyla kaynama sırasında impaksiyon ve varus sık görülen komplikasyonlardır. ${ }^{[15]}$ Yanlış kaynama (malunion) geç dönem ağrı sebeplerinden biridir.[16] Trokanter majorün görece uzunluğuna bağlı abduktor mekanizma problemleri ve ağrı görülebilmektedir. ${ }^{[17]}$ Trokanterik kaydırma ya da çeşitli femur osteotomileri veya artroplasti tedavi seçenekleri arasındadır. ${ }^{[18]}$

\section{PROTEZ SONRASI AĞRILI KALÇA SEBEPLERI}

Kalça kırığı sonrası protez uygulanan hastaların ortalama \%27'sinde ameliyat sonrası 6. aya kadar ağrı olmakla birlikte, \%4-6'sında ciddi kronik ağrı gözlenmektedir. ${ }^{[19,20]}$ Kalça protezi sonrası revizyon sebepleri arasında ağrı \%19,5 oranında görülürken, aseptik gevşeme $\% 50,3$ ve enfeksiyon $\% 15,9$ oranında tespit edilmiştir. ${ }^{[21]}$

Kalça protez cerrahisi sonrası ağrı dışsal veya içsel sebeplerle oluşabilir. Dışsal ağrı sebeplerinin \%25'i genellikle spinal stenoz, disk herniasyonu, spondilolizis veya spondilolistezis gibi omurga patolojileridir. ${ }^{[5]}$ Yakın komşuluk sebebiyle her iki bölgenin ağrılarının iç içe geçmesi tanıyı güçleştirirken kliniği de kötüleştirmektedir. ${ }^{[22]}$

İçsel sebepler kapsül içi sorunlar ve kapsül dışı sorunlar olarak ikiye ayrılabilir Kapsül içi sorunlar komponentler ile ilgili problemler, enfeksiyon, gevşeme, instabilite ve implant yetmezliği sebebiyle oluşmaktadır. ${ }^{[23]}$ Kapsül dışı sorunlar arasında iliopsoas 
Tablo 1. Kalça protez cerrahisi sonrası ağıı sebepleri[ ${ }^{[23]}$

\begin{tabular}{lll}
\hline $\begin{array}{l}\text { İçsel } \\
\text { sebepler }\end{array}$ & Kapsül içi sebepler & $\begin{array}{l}\text { Enfeksiyon } \\
\text { Gevşeme, } \\
\text { İnstabilite } \\
\text { İmplant yetmezliği } \\
\text { Kapsül dışı sebepler }\end{array}$ \\
$\begin{array}{l}\text { Iliopsoas tendinit } \\
\text { Trokanterik bursit } \\
\text { Heterotopik ossifikasyon } \\
\text { sebepler }\end{array}$ & $\begin{array}{l}\text { Omurga sorunları } \\
\text { Herniler }\end{array}$ \\
& $\begin{array}{l}\text { Vasküler hastalıklar } \\
\text { Periferal nöropati } \\
\text { Kötü huylu tümörler }\end{array}$ &
\end{tabular}

tendonu ve trokanterik bursa gibi yumuşak doku sorunları ve heterotopik ossifikasyon sayılabilir (Tablo 1 ). Ameliyat sonrası en az 6 aydır var olan ve açıklanamayan ağrılı total kalça artroplastisine sahip 194 hastanın 201 kalçasının incelendiği bir çalışmada tüm ağrı sebepleri arasında hastaların \%26,4'ünde periartiküler ağrı, \%24,4'ünde yansıyan ağrı gözlenmişken; enfeksiyon \%3, gevşeme \%10, mikroinstabilite \%1,5, materyallerde yıpranma \%20 ve metallozis \%9 olarak bulunmuştur. ${ }^{[5]}$

Ağrının lokalizasyonunun araştırılması tanı koymada yardımcı olabilir. Ağrının yeri (kasık veya uyluk ağrısı), aktiviteye bağımlı olup olmaması, ağrının tipi (mekanik, yangısal, yanıcı tarzda, derin) ve analjeziklere verdiği cevap sorgulanmalıdır. Kasık ağrısı asetabular komponentteki gevşeme, iliopsoas sıkışma veya tendiniti, inguinal herni, psoas apsesi, genito-üriner sorunlar ve vasküler patoloji sebebiyle olabilir. ${ }^{[5]}$ Uyluk ağrısı femoral komponentte aseptik gevşeme veya instabilite, sinir hasarı (örn., lateral femoral kutanöz sinir) veya spinal stenoza bağlı radikülopati sebebiyle oluşabilir. Aseptik gevşeme, stres kırıkları ve implant instabilitesi sıklıkla mekanik ağrıya sebep olurken, enfeksiyon ve tümoral oluşumlarda ise istirahat ağrısı gözlenebilir. Yanıcı ağrılarla birlikte bacağa yansıyan uyuşukluk lomber bölge problemlerinde izlenirken, ani ve keskin ağrı periprostetik (protez çevresi) kırıklar veya yumuşak doku irkiltmesini (irritasyon) düşündürmektedir. Derin rahatsız edici ağrılar enfeksiyon ve/veya osteoliz sebebiyle olabilir. ${ }^{[19]}$

Fizik muayenede antaljik yürüyüş veya Trendelenburg yürüyüşü, oturma veya koltuktan kalkarken ağrı mevcudiyeti değerlendirilmelidir. Merdiven inme-çıkma veya oturma pozisyonundan kalkma sonrası ortaya çıkan ağrı, iliopsoas tendinitini düşündürebilir.
Hareketle artan ve dinlenmeyle azalan ağrı komponent gevşemesini düşündürürken belli bir aktivite seviyesi sonrası ortaya çıkan ağrılar vasküler veya nörojenik kladikasyo sebebiyle olabilir. ${ }^{[19]}$ Kalça dışı sebepleri ekarte etmek için laseque testi, fleksiyon-iç rotasyon, fleksiyon-dış rotasyon, ekstansiyon-rotasyon hareket muayenesi yapılmalıdır.

İyi bir fizik muayene sonrası basit görüntüleme yöntemleriyle ağrılı kalça sebepleri veya ayırıcı tanılar ekarte edilebilir. Aseptik gevşemelerde progresif (artan) radyolusen çizgiler, sement kırıkları ve komponentlerin migrasyonu veya osteolitik alanlar görülebilir. Mikro hareket sonrası ortaya çıkan aseptik gevşemede kortikal kalınlaşma veya sklerotik çizgilenmeler izlenebilir. ${ }^{[24]}$ Ağrı hareketle veya yük verme sonrası artar. Hastalarda ameliyattan hemen sonra ağrısız bir dönem mevcuttur. Ağrı bazen gece uyandıracak kadar fazla olabilir. ${ }^{[4]}$

Septik gevşemelerde multilamellar periosteal yeni kemik oluşumu görülürken ağrı erken veya geç başlangıçlı enfeksiyon döneminden sonra ortaya çıkar. ${ }^{[25]}$ Hemiartroplasti sonrası enfeksiyon \%1,7- \%7,2 oranında izlenmekte olup total kalça protezinden daha sık görülmektedir. ${ }^{[26,27]}$ Enfeksiyon ve dolayısıyla ameliyat sonrası (postoperatif) ağrı riskinin azaltılması uygun antibiyotik profilaksisi ve kısa cerrahi süre ile sağlanabilir. Yüzeyel yara yeri enfeksiyonları için oral ya da i.v. antibiyoterapiler ön planda iken derin dokuyu etkileyen enfeksiyonlarda ve apse oluşumunda tedavi hareketli parçaların değiştirilmesi, yıkama ve debridman ve ikinci basamakta gerekirse revizyon cerrahileri planlanmalıdır.

Heterotopik ossifikasyon radyolojik olarak hastaların \%90'ında görülse de, olguların yalnızca \%9'unda ağrı sebebi olduğu bilinmektedir. ${ }^{[28]}$ Radyolojik olarak tanı koyulabilecek diğer bir sebep stres kalkanı (stress shielding) oluşumudur. Femoral stem sebebiyle olan yüklenmeye kemiğin adaptif cevabı sebebiyle oluşan bu durum radyolojik olarak femoral stemin proksimalinde rezorpsiyon ve distalinde kemik hipertrofisi şeklinde ortaya çıkmaktadır. ${ }^{[29]}$ Tanı konulamayan hastalarda bilgisayarlı tomografi (BT), manyetik rezonans (MR) veya sintigrafi gibi ileri görüntüleme yöntemleri tercih edilebilir.

Anatomik periartiküler (eklem çevresi) sebepler arasında orantısal olarak en sık görülen ağrı sebebi trokanterik bursitlerdir (\%20). ${ }^{[5]}$ Kalça protez ameliyatı sonrası büyük trokanter etrafında lokalize olan ağrı "trokanterik ağrı sendromu" olarak adlandırılır. Uygun olmayan offsetin kalça dinamiklerini bozarak ağrıya sebep olduğu düşünülmektedir. Özellikle total kalça protezi ameliyatı sonrası global femoral 
offsetin karşı kalçaya göre 5 mm'den fazla azalması ve bacak uzunluk eşitsizliğinin $11 \mathrm{~mm}$ 'den fazla olması trokanterik bursit oluşma riskini artırmakla beraber abduktor kuvvette azalmaya yol açıp yardımcı yürüme araçları kullanılmasına sebep olmaktadır. ${ }^{[30]}$ Kortikosteroid enjeksiyonu ile şikâyetler $\% 80$ oranında azalmasına rağmen \%20 hastada artroskopik bursektomi veya gluteal fasya transpozisyonu gibi ek cerrahilere gerek olabilmektedir. ${ }^{[31]}$ Abduktor kas hasarları, iliopsoas tendinitleri, sinir hasarları ve yansıyan ağrılar diğer kemik ve protez dışı ağrı sebepleri arasında sayılabilir.

Bacak uzunluk eşitsizliği ve kalça ağrısı üzerine yapılan birden çok çalışmada farkın fazla olmasının kötü Harris kalça skorlarına sebep olduğu ortaya konulurken $>9 \mathrm{~mm}^{[32]},>10 \mathrm{~mm}^{[33]}$ veya $>20 \mathrm{~mm}$ üzerinde ağrıya sebep olduğunu bildiren yayınlar mevcuttur. Hemiartroplasti ameliyatlarında bacak uzunluğunun ayarlanması da ağrının azaltılması için önem arz etmektedir. Bu sebeple mümkün olduğunca karşı ekstremite ile uzunluğun eşitlenmesi ağrıyı ortadan kaldırmaya yardımcı olacaktır.

Sonuç olarak, yaşı ıasta kalça kırık ameliyatları sonrası kronik ağrı sebepleri değerlendirildiğinde ağrının hasta, cerrah ve kullanılan materyallerle ilişkili olduğu görülebilmektedir. Ameliyat öncesi iyi bir hasta eğitimi, ameliyat esnasında kalça ekleminin biyomekanik özelliklerini sağlayacak özenli bir cerrahi ve uygun bir implant seçimi hastaların şikâyetlerini oldukça azaltacaktır.

\section{KAYNAKLAR}

1. Stevens JA, Rudd RA. The impact of decreasing U.S. hip fracture rates on future hip fracture estimates. Osteoporos Int 2013;24(10):2725-8. Crossref

2. Bonar SK, Tinetti ME, Speechley M, Cooney LM. Factors associated with short- versus long-term skilled nursing facility - placement among community-living hip fracture patients. J Am Geriatr Soc 1990;38(10):1139-44. Crossref

3. Classification of chronic pain. Descriptions of chronic pain syndromes and definitions of pain terms. Prepared by the International Association for the Study of Pain, Subcommittee on Taxonomy. Pain Suppl 1986;3:S1-226. https://pubmed. ncbi.nlm.nih.gov/3461421/

4. Duffy P, Masri BA, Garbuz D, Duncan CP. Evaluation of patients with pain following total hip replacement. Instr Course Lect 2006;55:223-32. https://pubmed.ncbi.nIm.nih. gov/16958458/

5. Erivan R, Villatte G, Ollivier M, Paprosky WG. Painful Hip Arthroplasty: What Should We Find? Diagnostic Approach and Results. J Arthroplasty 2019;34(8):1802-7. Crossref

6. Haidukewych GJ, Berry DJ. Hip arthroplasty for salvage of failed treatment of intertrochanteric hip fractures. J Bone Joint Surg Am 2003;85(5):899-904. Crossref

7. Thirukumaran CP, Zaman A, Rubery PT, Calabria C, Li Y, Ricciardi BF, Bakhsh WR, Kautz H. Natural Language Processing for the Identification of Surgical Site Infections in Orthopaedics. J Bone Joint Surg Am 2019;101(24):2167-74. Crossref
8. Chen AF, Brown GA. Management of Surgical Site Infections. J Am Acad Orthop Surg 2020;28(6):e238-41. Crossref

9. Zimmerli W, Sendi P. Orthopaedic biofilm infections. APMIS 2017;125(4):353-64. Crossref

10. Bhowmick K, Matthai T, Boopalan PRJ, Jepegnanam TS. Decision making in the management of malunion and nonunion of intertrochanteric fractures of the hip. Hip Int 2020;30(6):793-8. Crossref

11. DeLee JC. Fractures and dislocations of the hip. In: Rockwood CA Jr, Green DP, Bucholz RW, Heckman JD, editors. Rockwood and Green's fractures in adults. Vol. 2, 4th ed. Philadelphia: Lippincott-Raven; 1996. p. 1659-825.

12. Weiss RJ, Kärrholm J, Hailer NP, Beckman MO, Stark A. Salvage of failed trochanteric and subtrochanteric fractures using a distally fixed, modular, uncemented hip revision stem. Acta Orthop 2012;83(5):488-92. Crossref

13. Socci AR, Casemyr NE, Leslie MP, Baumgaertner MR. Implant options for the treatment of intertrochanteric fractures of the hip: rationale, evidence, and recommendations. Bone Joint J 2017;99-B(1):128-33. Crossref

14. Caruso G, Bonomo M, Valpiani G, Salvatori G, Gildone A, Lorusso V, Massari L. A six-year retrospective analysis of cut-out risk predictors in cephalomedullary nailing for pertrochanteric fractures: Can the tip-apex distance (TAD) still be considered the best parameter? Bone Joint Res 2017;6(8):481-8. Crossref

15. Lenich A, Mayr E, Rüter A. Der Wechsel von Osteosynthese zur Prothese bei hüftnahen Femurfrakturen - ein einfaches Verfahren? [Hip replacement after failed internal fixation in patients with proximal femur fracture--a simple procedure?]. Zentralbl Chir 2002;127(6):503-6. German. Crossref

16. Mayo K, Kuldjanov D. Generic Preoperative Planning for Proximal Femoral Osteotomy in the Treatment of Nonunion of the Femoral Neck. J Orthop Trauma 2018;32 Suppl 1:S4654. Crossref

17. Bartonícek J, Skála-Rosenbaum J, Dousa P. Valgus intertrochanteric osteotomy for malunion and nonunion of trochanteric fractures. J Orthop Trauma 2003;17(9):606-12. Crossref

18. Dziadosz D. Considerations with failed intertrochanteric and subtrochanteric femur fractures: how to treat, revise, and replace. J Orthop Trauma 2015;29 Suppl 4:S17-21. Crossref

19. Wylde V, Hewlett S, Learmonth ID, Dieppe P. Persistent pain after joint replacement: prevalence, sensory qualities, and postoperative determinants. Pain 2011;152(3):566-72. Crossref

20. Palazzo C, Jourdan C, Descamps S, Nizard R, Hamadouche M, Anract P, Boisgard S, Galvin M, Ravaud P, Poiraudeau S. Determinants of satisfaction 1 year after total hip arthroplasty: the role of expectations fulfilment. BMC Musculoskelet Disord 2014;15(1):53. Crossref

21. Evans JT, Evans JP, Walker RW, Blom AW, Whitehouse MR, Sayers A. How long does a hip replacement last? A systematic review and meta-analysis of case series and national registry reports with more than 15 years of follow-up. Lancet 2019;393(10172):647-54. Crossref

22. Parvizi J, Pour AE, Hillibrand A, Goldberg G, Sharkey PF, Rothman RH. Back pain and total hip arthroplasty: a prospective natural history study. Clin Orthop Relat Res 2010;468(5):1325-30. Crossref

23. Lam YF, Chan PK, Fu H, Yan $\mathrm{CH}$, Chiu KY. A review of the clinical approach to persistent pain following total hip replacement. Hong Kong Med J 2016;22(6):600-7. Crossref 
24. Ferrata P, Carta S, Fortina M, Scipio D, Riva A, Di Giacinto S. Painful hip arthroplasty: definition. Clin Cases Miner Bone Metab 2011;8(2):19-22. https://www.ncbi.nlm.nih.gov/ pmc/articles/PMC3279074/

25. Garvin KL, Backstein D, Pellegrini VD Jr, Kim RH, Lewallen DG. Dealing with complications. J Bone Joint Surg Am 2009;91 Suppl 5:18-21. Crossref

26. Ridgeway S, Wilson J, Charlet A, Kafatos G, Pearson A, Coello R. Infection of the surgical site after arthroplasty of the hip. J Bone Joint Surg Br 2005;87-B(6):844-50. Crossref

27. Cordero-Ampuero J, de Dios M. What are the risk factors for infection in hemiarthroplasties and total hip arthroplasties? Clin Orthop Relat Res 2010;468(12):3268-77. Crossref

28. Bozic KJ, Rubash HE. The painful total hip replacement. Clin Orthop Relat Res 2004;420:18-25. Crossref

29. Engh CA Jr, Young AM, Engh CA Sr, Hopper RH Jr. Clinical consequences of stress shielding after porous-coated total hip arthroplasty. Clin Orthop Relat Res 2003;(417):157-63. https://pubmed.ncbi.nlm.nih.gov/14646713/
30. Mahmood SS, Mukka SS, Crnalic S, Wretenberg P, SayedNoor AS. Association between changes in global femoral offset after total hip arthroplasty and function, quality of life, and abductor muscle strength. A prospective cohort study of 222 patients. Acta Orthop 2016;87(1):36-41. Crossref

31. Farmer KW, Jones LC, Brownson KE, Khanuja HS, Hungerford MW. Trochanteric bursitis after total hip arthroplasty: incidence and evaluation of response to treatment. J Arthroplasty 2010;25(2):208-12. Crossref

32. Mahmood SS, Mukka SS, Crnalic S, Sayed-Noor AS. The Influence of Leg Length Discrepancy after Total Hip Arthroplasty on Function and Quality of Life: A Prospective Cohort Study. J Arthroplasty 2015;30(9):1638-42. Crossref

33. Warnock J, Hill J, Humphreys L, Gallagher N, Napier R, Beverland D. Independent restoration of femoral and acetabular height reduces limb length discrepancy and improves reported outcome following total hip arthroplasty. J Orthop 2019;16(6):483-8. Crossref 